\title{
Electrocaloric effect in La-doped BNT-6BT relaxor ferroelectric ceramics
}

\author{
Lucheng $\mathrm{Li}^{1}$, Mengxing Xu ${ }^{1}$, Qi Zhang ${ }^{2}$, Ping Chen ${ }^{1}$, Biaolin Peng ${ }^{1 *}$, Laijun Liu ${ }^{1 *}$ \\ ${ }^{1}$ Guangxi Key Laboratory for Relativistic Astrophysics, School of Physical Science \& \\ Technology, Guangxi University, Nanning 530004, China. \\ ${ }^{2}$ Department of Manufacturing and Materials, Cranfield University, Cranfield, \\ Bedfordshire, MK43 0AL, United Kingdom. \\ *Correspondence to: pengbL8@126.com; ljliu2@163.com
}

Abstract: Relaxor $\left[\left(\mathrm{Bi}_{1 / 2} \mathrm{Na}_{1 / 2}\right)_{0.94} \mathrm{Ba}_{0.06}\right]_{(1-1.5 \mathrm{x})} \mathrm{La}_{\mathrm{x}} \mathrm{TiO}_{3}(\mathrm{x}=0,0.03,0.06,0.09)$ ceramics (La-doped BNT-6BT hereafter) with composition close to the morphotropic phase boundary (MPB) were successfully prepared by using the conventional solid state reaction method. All samples present almost a pure perovskite phase with coexistence of tetragonal and rhombohedral. With the increase of La doping content, the degree of the dielectric relaxor dispersion around the dielectric peak which is close to the room temperature increases, and also the transition temperature of ferroelectric-to-relaxor $\left(T_{F-R}\right)$ shifts $120 \mathrm{~K}$ towards a lower temperature at $\mathrm{x}=0.09$. The maximum value of the temperature change $(\Delta T)$ of the electrocaloric $(E C)$ effect decreases sharply from $1.1 \mathrm{~K}$ at $\mathrm{x}=0$ to $0.064 \mathrm{~K}$ at $\mathrm{x}=0.09$. A large positive $E C$ effect (maximum $\Delta T \sim 0.44 \mathrm{~K}$ ) in a broad temperature range $(\sim 90 \mathrm{~K})$ close to room temperature is achieved at $\mathrm{x}=0.03$, indicating that it is a promising lead-free material for application in solid state cooling system. Moreover, it is found that the Maxwell relationship can be well used to assess the $E C$ effects of the La-doped BNT-6BT 
ceramics when the operating temperature is higher than that of the $T_{F-R}$, indicating that these relaxor ceramics would perform as an ergodic.

Keywords: Relaxor ferroelectric, MPB, Lead-free, Broad temperature range

\section{Introduction}

The $E C$ effect has been of much interest in cooling systems. It can be designed to substitute conventional mechanical vapor compression cycle cooling devices such as refrigerators and air conditioners which release a large number of greenhouse gases during their operation [1]. In the past, the bottleneck for the development of $E C$ cooling technologies was that only small temperature $(\Delta T)$ and entropy changes $(\Delta S)$ could be induced in bulk materials by virtue of the low breakdown electric field [2]. Fortunately, a giant $E C$ effect in a $\mathrm{PbZr}_{0.95} \mathrm{Ti}_{0.05} \mathrm{O}_{3}(\mathrm{PZT})$ thin film with a large $\Delta T$ of $12 \mathrm{~K}$ was first reported by Mischenko et al. in 2006, which revived great interest in this field [3]. Further research activities lead to even larger $\Delta T$ and $\Delta S$ in $\mathrm{Pb}_{0.8} \mathrm{Ba}_{0.2} \mathrm{ZrO}_{3}(\mathrm{PBT}) \quad[1], \quad \mathrm{Pb}\left(\mathrm{Sc}_{0.5} \mathrm{Ta}_{0.5}\right) \mathrm{O}_{3}(\mathrm{PST})$ [4], $\mathrm{Pb}\left(\mathrm{Mg}_{1 / 3} \mathrm{Nb}_{2 / 3}\right)_{0.65} \mathrm{Ti}_{0.35} \mathrm{O}_{3}$ (PMN-PT) [5] and $\left(\mathrm{Pb}_{0.88} \mathrm{La}_{0.08}\right)\left(\mathrm{Zr}_{0.65} \mathrm{Ti}_{0.35}\right) \mathrm{O}_{3}$ (PLZT) [6], etc.Similar $\Delta T$ values were also reported in copolymers $(\mathrm{P}(\mathrm{VDF}-\mathrm{TrFE}))[7,8]$ and terpolymers $(\mathrm{P}(\mathrm{VDF}-\mathrm{TrFE}-\mathrm{CFE}))[9,10]$. However, when the electrocaloric coefficient $(\Delta T / \Delta E)$ is taken into consideration, it becomes clear that inorganic oxides are much better $E C$ materials [11] compared to polymers. In recent years, in order to respond to the European "RoHS/WEEE" environmental and health protection directive, lead-free ferroelectric materials have been extensively researched and rapidly developed in $E C$ 
effect, energy storage and piezoelectricity, etc.

Lead-free solid solutions based on the perovskites, such as $\mathrm{BaTiO}_{3}$ (BT), $\mathrm{Bi}_{0.5} \mathrm{Na}_{0.5} \mathrm{TiO}_{3}(\mathrm{BNT}), \mathrm{K}_{0.5} \mathrm{Na}_{0.5} \mathrm{NbO}_{3}(\mathrm{KNN})$ and $\mathrm{Bi}_{0.5} \mathrm{~K}_{0.5} \mathrm{TiO}_{3}(\mathrm{BKT})$ are promising environmentally friendly ferroelectrics that have been intensively researched [12-15]. Among them, 0.94( $\left(\mathrm{Bi}_{1 / 2} \mathrm{Na}_{1 / 2}\right) \mathrm{TiO}_{3}-0.06 \mathrm{BaTiO}_{3}(\mathrm{BNT}-\mathrm{BT})$ ceramics have been widely studied to replace the lead-based ceramics. Numerous researchers have focused on compositional modifications to improve the performance of the BNT-BT system [16, 17]. It was found that the materials with the composition near the MPB coexisting with rhombohedral and tetragonal phase structures can result in good performance on $E C$ effects and typical relaxation properties. For example, $0.935 \mathrm{Bi}_{0.5} \mathrm{Na}_{0.5} \mathrm{TiO}_{3}-0.065 \mathrm{BaTiO}_{3}-\mathrm{SrTiO}_{3}(\mathrm{BNBST})$

$\mathrm{Ba}_{0.5} \mathrm{Na}_{0.5} \mathrm{TiO}_{3}-\mathrm{xBaTiO} 3(\mathrm{BNT}-\mathrm{xBT})[19]$ and $\left(\mathrm{Na}_{0.5} \mathrm{Bi}_{0.5}\right)_{1-\mathrm{x}} \mathrm{Ba}_{\mathrm{x}} \mathrm{TiO} 3$ (BNBT) [20, 21], etc.

Apart from the perovskites above mentioned, the EC effect of other perovskite materials, such as $\mathrm{Pb}\left(\mathrm{Sc}_{0.5} \mathrm{Ta}_{0.5}\right) \mathrm{O}_{3} \quad$ (PST) [22], $\mathrm{BaTiO}_{3} \quad$ (BT) [23] and (1-x) $\left(\mathrm{Na}_{0.5} \mathrm{Bi}_{0.5}\right) \mathrm{TiO}_{3}-\mathrm{xKNbO}$ [24], etc., have also been considered. Along with large $\Delta T$ and $\Delta S$, a broad operable temperature range is required in practical cooling application as well. La has been used to modify several archetypal perovskites, such as $\mathrm{Pb}(\mathrm{Zr}, \mathrm{Ti}) \mathrm{O}_{3}$ and $\mathrm{Ba}_{1 / 2} \mathrm{Na}_{1 / 2} \mathrm{TiO}_{3}$ [25-27]. Its isovalent and aliovalent doping has shown to be a reliable strategy to tailor the dielectric, pyroelectric and relaxor properties of the BNT based ceramics. For instance, $\left(\mathrm{Bi}_{0.94-\mathrm{x}} \mathrm{La}_{\mathrm{x}} \mathrm{Na}_{0.94}\right)_{0.5} \mathrm{Ba}_{0.06} \mathrm{TiO}_{3}$ [25-xxx], La-doped $\quad \mathrm{Bi}_{1 / 2}\left(\mathrm{Na}_{0.82} \mathrm{~K}_{0.18}\right)_{1 / 2} \mathrm{TiO}_{3} \quad[28]$ and La-doped 
$\mathrm{Bi}_{1 / 2} \mathrm{Na}_{1 / 2} \mathrm{TiO}_{3}-\mathrm{BaTiO}_{3}-\mathrm{SrZrO}_{3}[29]$, etc.

In this study, an A-site La doped $\left[\left(\mathrm{Bi}_{1 / 2} \mathrm{Na}_{1 / 2}\right)_{0.94} \mathrm{Ba}_{0.06}\right]_{(1-1.5 \mathrm{x})} \mathrm{La}_{\mathrm{x}} \mathrm{TiO}_{3}(\mathrm{x}=0,0.03,0.06$, 0.09) system is designed to obtain a wider operating temperature range. It can be concluded that La doping makes the dielectric relaxor dispersion around the dielectric peak near room temperature more diffuse and reduces the $T_{F-R}$ by nearly $120 \mathrm{~K}$ at $\mathrm{x}=$ 0.09. The maximum value of $\Delta T$ decreases sharply from $1.1 \mathrm{~K}$ at $\mathrm{x}=0$ to $0.064 \mathrm{~K}$ at $\mathrm{x}$ $=0.09$. The La-doped BNT-6BT ceramics at $\mathrm{x}=0.03$ presents a large positive $E C$ effect (maximum $\Delta T \sim 0.44 \mathrm{~K})$ in a broad temperature range $(\sim 90 \mathrm{~K})$ at near room temperature, which makes it more practical for solid state $E C$ effect in the future applications. Moreover, it is found that the Maxwell relationship could be well applied to assess the $E C$ effects of the La-doped BNT-BT ceramics when the value of the operating temperature is higher than that of the $T_{F-R}$ where relaxor ceramics perform at the almost ergodic state.

\section{Experimental process}

La-doped BNT-6BT ceramics were prepared by conventional solid state reaction method. The starting materials were $\mathrm{BaCO}_{3}$ (purity $\geq 99 \%$ ), $\mathrm{La}_{2} \mathrm{O}_{3}$ (purity $\geq 99.5 \%$ ), $\mathrm{Na}_{2} \mathrm{CO}_{3}$ (purity $\geq 99.8 \%$ ), $\mathrm{Bi}_{2} \mathrm{O}_{3}$ (purity $\geq 99 \%$ ) and $\mathrm{TiO}_{2}$ (purity $\geq 99 \%$ ). The raw materials were weighed at a stoichiometric ratio and then ball milled in a nylon tank with the zirconia balls as media in ethanol for 4 hours. The dried slurries were calcined at $900{ }^{\circ} \mathrm{C}$ for 6 hours and ball milled again for 12 hours to dissociate the agglomerates. After further drying, the ceramic powders were pressed in a steel mold 
with $300 \mathrm{MPa}$ for $60 \mathrm{~s}$ into green disks with10 $\mathrm{mm}$ in diameter and $1 \mathrm{~mm}$ in thickness All the pellets were then sintered at $1150{ }^{\circ} \mathrm{C}$ for 6 hours with a heating rate of 3 ${ }^{\circ} \mathrm{C} / \mathrm{min}$, and then cooled to room temperature naturally.

The density of the samples was measured by the Archimedean drainage method. The phase structure of ceramics was analyzed by an X-ray diffractometer (XRD, X'Pert PRO MPD, Philips, Eindhoven, Netherlands). The microstructure of the ceramics was observed by a field emission scanning electron microscopy (JEOL-6700F, Japan Electron Co, Tokyo, Japan). The dielectric response was measured using a precision impedance analyzer (4294A, Agilent, CA, USA). The temperature control was performed using a temperature controller (TP94, Linkam, Surrey, UK) with an excitation voltage of $500 \mathrm{mV} / \mathrm{mm}$, with the frequency and temperature acquisition ranging from $100 \mathrm{~Hz}$ to $1 \mathrm{MHz}$ and $213 \mathrm{~K}$ to $720 \mathrm{~K}$ with a ramp rate of $3 \mathrm{~K} / \mathrm{min}$ respectively. The hysteresis loops $(P-E)$ were tested using a ferroelectric analyzer (TF-2000, AixACCT, Aachen, Germany) at a frequency of $1 \mathrm{~Hz}$.

\section{Results and analysis}

\subsection{Structure and morphology}

Figure 1 a) shows the XRD patterns of sintered La-doped BNT-6BT ceramics. From the XRD patterns, it can be seen that after 6 hours sintering at $1150^{\circ} \mathrm{C}$ all the components were pure phase perovskite structure without pyrochlore phase coexisting. (001) and (002) diffraction peaks of La doped BNT-6BT ceramics gradually shifted to the low-angle direction with the increase of La content which indicates the increase of 
its pseudocubic lattice parameter a. The structure of BNT system is rhombohedral and that of BT is tetragonal at room temperature [30]. A rhombohedral-tetragonal MPB exists in their solid solutions near the BNT-6BT composition [31]. From Figure 1 b), it can be seen that both reflections at about $40.2^{\circ}$ and $46.6^{\circ}$ exhibit the feature of peaks splitting, which could be assigned to the (003) and (021) reflections of the rhombohedral phase and (002) and (200) reflections of the tetragonal phase, respectively. This result reveals that the La-doped BNT-6BT ceramics remain in the coexistence of the rhombohedral-tetragonal phases as in BNT-6BT ceramics.

Figure 2 shows the SEM images of La-doped BNT-6BT ceramics after the thermal etching (1100 ${ }^{\circ} \mathrm{C}$ insulation for $6 \mathrm{~h}$ ). The SEM images show that the La-doped BNT-6BT ceramics have a dense microstructure with nearly uniform grain size. With the increase of La content, the plate-like grains first increase and then decrease, and the the largest plate-like number appeared at $\quad \mathrm{x}=0.06$. The average size of plate-like grains of La-doped BNT-6BT ceramic samples remained roughly the same with an average size of 3 microns, indicating that the grain size might not play an important role so that it could affect the electrocaloric properties of La-doped BNT-6BT ceramics.

\subsection{Dielectric properties}

Figures 3 depicts the temperature dependence of the dielectric constant $(\varepsilon(T))$ and the dielectric loss $(\tan \delta(T))$ of the La-doped BNT-6BT ceramics at different frequencies. The $\varepsilon(T)$ curves of all the samples show a strong frequency dispersion in the 
low-temperature region and a weak frequency dispersion in the high-temperature region. The study results of Wook et al. [20] show that there may be two independent relaxation processes in the different temperature ranges. The dielectric anomaly at the temperature near the dielectric permittivity maximum $\left(T_{\mathrm{m}}\right)$ corresponding to high-temperature dielectric constant peak is related to a relaxation of tetragonal polar nanoregions (PNRs) emerged from rhombohedral PNRs and the other dielectric anomaly at lower temperatures is due to thermal evolutions of discrete PNRs. Recent studies demonstrated that the dielectric anomaly at lower temperatures should be referred to as ferroelectric-to-relaxor transition temperature $\left(T_{F-R}\right)$ rather than depolarization temperature $\left(T_{d}\right)[32,33]$. The two dielectric anomalies on the dielectric $\varepsilon(T)$ curves are always observed in the BNT-based ceramics. Three consecutive events are expected to happen during heating. The initially existing mixture of polar R3c rhombohedral clusters and a weakly polar or ferrielectric P4bm tetragonal matrix undergo a thermal evolution resulting in the first broad dielectric maximum, followed by a transition of R3c to P4bm PNRs, and finally all the P4bm symmetries undergo a thermal evolution giving rise to the second frequency-dispersive dielectric maximum [20]. The nanodomains in the P4bm phase are actually uncompensated antiferroelectric, or weakly polar ferrielectric domains [34]. As a result, the dielectric behavior of the P4bm relaxor antiferroelectric phase is similar to that of a relaxor ferroelectric in many aspects. Ma and Tan have proposed a "relaxor antiferroelectric" term to describe the dielectric behavior of the P4bm phase for its strong frequency dispersion in their previous works $[35,36]$. 
With the increase of La content, the dielectric diffusion peak of $T_{F-R}$ shifts to the low temperature direction, while the peak of $T_{m}$ shifts to the high temperature direction. Broad dielectric constant peak could be well observed and indicates a diffused phase transition behavior. This might be originated from compositionally induced ferroelectric to diffused phase transition, and multiple complexes in the A-site of perovskite compounds is another reason [37, 38]. At the temperature higher than $T_{m}$, the dielectric loss of La-doped BNT-6BT increases abnormally with the temperature increasing, which could be attributed to high conduction property in the high temperature region [30].

In Lorentz function $\varepsilon_{A} / \varepsilon=1+\left(T-T_{A}\right)^{2} / 2\left(\delta_{A}\right)^{2}[39,40], \varepsilon(T)$ curves could be decomposed into two parts due to the contributions of high and low temperatures respectively. Dot lines in Figure 3 show the Lorentz decomposition of the $\varepsilon(T)$ curves at $100 \mathrm{~Hz}$ and Table 1 shows the fitting of the Lorentz parameter for $\varepsilon(T)$ curves. As can be seen from the Table 1, the $\delta_{\mathrm{A}}$ of La-doped BNT-6BT ceramics gradually increases from 80 of the composition $\mathrm{x}=0$ to 118 of the composition $\mathrm{x}=0.09$, indicating that the addition of La improves the relaxation dispersion of the system on the other hand.

\subsection{Electrocaloric Effect}

In order to study the electrocaloric effect of La-doped BNT-6BT, the hysteresis loops $(P-E)$ during temperature rising at the interval of $30 \mathrm{~K}$ were measured as shown in Figures 4 a)-d). At $x=0$, there is an evident double-like hysteresis loops above $330 \mathrm{~K}$ accompanying phase transformation from ferroelectric $\mathrm{R} 3 \mathrm{c}$ phase to antiferroelectric P4bm phase. One abnormal behavior is that the values of maximum polarization $\left(P_{\max }\right)$ 
increase with temperature, and then decrease, as depicted in Figure 4 a). This abnormal behavior is also observed by Bai et al.[23], which is caused by the phase transition induced by the external field from ferroelectric (FE) to antiferroelectric (AFE). At $\mathrm{x}=0.03,0.06$ and 0.09 , the $P-E$ loops become much slimmer compared to the unmodified BNT-6BT, indicating that the La substitution causes the lattice distortion and disrupts the dominant ferroelectric long-range-order leading to a decrease in the remnant polarization and maximum polarization [41]. However, the ergodic phase dominates at higher La contents $(\mathrm{x}=0.06,0.09)$ as confirmed by the drastic reduction in the maximum polarization, resulting in the delay transformation of relaxor to ferroelectric phase $[42,43]$.

Under the condition of reversible adiabatic approximation, the Maxwell relational expression $(\partial P / \partial T)_{E}=(\partial S / \partial E)_{T}$ is assumed to be valid. The $E C$ effect of La doped BNT-6BT ceramics can be obtained from equations (1) and (2) [3, 7].

$$
\begin{aligned}
& \Delta T=-\frac{1}{\rho} \int_{E_{1}}^{E_{2}} \frac{T}{C}\left(\frac{\partial P}{\partial T}\right)_{E} d E \\
& \Delta S=-\frac{1}{\rho} \int_{E_{1}}^{E_{2}}\left(\frac{\partial P}{\partial T}\right)_{E} d E
\end{aligned}
$$

In equations (1) and (2), $T$ is the operating temperature, $P$ the maximum polarization at the applied electric field $E$, and $E_{1}$ and $E_{2}$ the initial and final applied electric field respectively. The density of $\left[\left(\mathrm{Bi}_{1 / 2} \mathrm{Na}_{1 / 2}\right)_{0.94} \mathrm{Ba}_{0.06}\right]_{(1-1.5 \mathrm{x})} \mathrm{La}_{\mathrm{x}} \mathrm{TiO}_{3}$ ceramics are: 5.1638 $\mathrm{g} / \mathrm{cm}^{3}(\mathrm{x}=0), 5.589 \mathrm{~g} / \mathrm{cm}^{3}(\mathrm{x}=0.03), 5.574 \mathrm{~g} / \mathrm{cm}^{3}(\mathrm{x}=0.06), 5.1736 \mathrm{~g} / \mathrm{cm}^{3}(\mathrm{x}=0.09)$. For simplicity, the heat capacity is assumed to be $0.45 \mathrm{~J} /(\mathrm{K} \cdot \mathrm{kg})$. The pyroelectric coefficient $\left((\partial P / \partial T)_{E}\right)$ could be obtained from the temperature dependence of 
polarization $(P(T))$, which are extracted from the upper branches of the $P-E$ loops in $E>0$. Figure 5 a) - d) are given for temperature dependence of pyroelectric coefficient $\left((\partial P / \partial T)_{E}(T)\right)$ curves of La-doped BNT-6BT ceramics at selected electric field. The illustrations correspond to $P(T)$ curves under selected electric fields, where the solid curves are the 6th order polynomial fitting of the $P(T)$ curves. It shows that the absolute value of $(\partial P / \partial T)_{E}$ decreases with the increase of La content. Overall, the $(\partial P / \partial T)_{E}$ value of the composition at $\mathrm{x}=0.03$ is not deviated far from that of unmodified BNT-6BT, but the values of $(\partial P / \partial T)_{E}$ reduce significantly for the composition at $\mathrm{x}=0.06,0.09$, anticipating a larger $E C E$ for composition at $\mathrm{x}=0.03$ compared to other modified BNT-6BT ceramics. Besides, it can be found that the electric field has little influence on the $(\partial P / \partial T)_{E}(T)$ curves, which promises a larger $\Delta T$ when it comes to the La-doped BNT-6BT thin film.

Figure 6 a) - d) show the temperature dependence of $\Delta T(T)$ of La-doped BNT-6BT ceramics under different electric fields. It can be found that the $\Delta T(T)$ curves with different electric fields are intertwined for all components in the lower temperature region, indicating a strong or middle interaction between the domains respectively. While in the higher temperature region, the $\Delta T(T)$ curves increase regularly with the electric field and show a good application of Maxwell relationship, implying a state similar to the ergodic state with weak interaction between domains. Moreover, seen from Figure 6 and Figure 3, an interesting phenomenon is found that the La-doped BNT-6BT ceramics would transform to an ergodic state with weak interaction between domains at the temperature close to $T_{F-R}$. For the composition at $\mathrm{x}=0$ in the 
vicinity of the morphotropic phase boundary, its $\Delta T$ appears negative value when the temperature is below $355 \mathrm{~K}$. The negative $E C$ effect has been found in other materials, it is attributed to the non-collinearity of the applied electric field and the polarization direction after the phase transition occurs from the rhombohedral to the tetragonal [44]. The temperature where the negative $E C$ effect vanished corresponds well with the pinching temperature of the $P-E$ loops shown in Figures 4 a), which could be attributed to the thermal evolution from polar $\mathrm{R} 3 \mathrm{c}$ rhombohedral clusters to antiferroelectric P4bm tetragonal phase. The original ferroelectric system with strong interaction between domains is disrupted by the increase of antiferroelectric P4bm phase, resulting in the reduction of the interaction between domains and the appearance of positive $E C$ effect. For the La doping components, it can be seen that there are two $\Delta T$ peaks in the temperature dependent curves, which are related to an increase in relaxation dispersion [22, 45-48]. La doping could make the transition happen easily in the low temperature and induce a decrease of $T_{F-R}$ for about $120 \mathrm{~K}$ at $\mathrm{x}=0.09$, which promises a large $E C$ effect near room temperature. The maximum value of the temperature change $(\Delta T)$ of the $E C$ effect decreases sharply from $1.1 \mathrm{~K}$ at $\mathrm{x}=0$ to $0.064 \mathrm{~K}$ at $\mathrm{x}=0.09$. On the whole, the La-doped ceramic with the composition at $\mathrm{x}=0.03$ is ideal, and La doping has reduced the $T_{F-R}$ of the ceramics from $456.9 \mathrm{~K}$ to $382.2 \mathrm{~K}$ for nearly $80 \mathrm{~K}$, and a large positive $E C$ effect (maximum $\Delta T \sim 0.44 \mathrm{~K})$ in a broad temperature range from $334.26 \mathrm{~K}$ to $427.59 \mathrm{~K}$ at the electric field of $51.97 \mathrm{KV} / \mathrm{cm}$. Its broader temperature range near room temperature and larger $\Delta T$ make it more likely to meet the actual needs. Figure 7 a) - d) show the 
temperature dependence of entropy variation $(\Delta S(T))$ of La-doped BNT-6BT ceramics under different electric fields. It can be found that the variation of $\Delta S$ is basically the same as that of $\Delta T$, so only the change relation diagrams were given here.

\section{Conclusion}

A broad operable temperature range near room temperature and large $\Delta T$ have been achieved in relaxor $\left[\left(\mathrm{Bi}_{1 / 2} \mathrm{Na}_{1 / 2}\right)_{0.94} \mathrm{Ba}_{0.06}\right]_{(1-1.5 \mathrm{x})} \mathrm{La}_{\mathrm{x}} \mathrm{TiO}_{3}(\mathrm{x}=0.03)$ ceramics prepared using the conventional solid state reaction method. The composition of the material was near the morphotropic phase boundary with the rhombohedral and tetragonal phase coexisting. It can be concluded that the La doping could make the dielectric relaxation dispersion around the dielectric peak near the room temperature more diffuse and decrease the $T_{F-R}$ for nearly $120 \mathrm{~K}$ at $\mathrm{x}=0.09$, resulting in a broader operational temperature range near room temperature. A large positive $E C$ effect (maximum $\Delta T \sim 0.44 \mathrm{~K})$ in a broad temperature range $(\sim 90 \mathrm{~K})$ close to room temperature is achieved at $\mathrm{x}=0.03$. The good $E C$ performance of the $\left[\left(\mathrm{Bi}_{1 / 2} \mathrm{Na}_{1 / 2}\right)_{0.94} \mathrm{Ba}_{0.06}\right]_{(1-1.5 \mathrm{x})} \mathrm{La}_{\mathrm{x}} \mathrm{TiO}_{3}(\mathrm{x}=0.03)$ relaxor ferroelectric ceramic may make it a promising lead free material for future applications in the cooling system. Moreover, it is found that the Maxwell relationship can be well used to assess the $E C$ effects of the La-doped BNT-6BT ceramics when the value of the operating temperature is higher than that of the $T_{F-R}$, indicating that these relaxor ceramics would perform as an ergodic.

\section{Acknowledgments}

This work was supported by the National Natural Science Foundation of China 
(51402196), the Guangxi Science Foundation (Grants 2016GXNSFCB380006 ), and the Scientific Research Foundation of Guangxi University (Grant XTZ160530).

\section{References}

[1] B.L. Peng, H.Q. Fan, Q. Zhang, A giant electrocaloric effect in nanoscale antiferroelectric and ferroelectric phases coexisting in a relaxor $\mathrm{Pb}_{0.8} \mathrm{Ba}_{0.2} \mathrm{ZrO}_{3}$ thin film at room temperature, Adv. Funct. Mater. 23 (23) (2013) 2987-2992.

[2] B.A. Tuttle, D.A. Payne, The effects of microstructure on the electrocaloric properties of $\mathrm{Pb}(\mathrm{Zr}, \mathrm{Sn}, \mathrm{Ti}) \mathrm{O}_{3}$ ceramics, Ferroelectrics 37 (1) (2011) 603-606.

[3] A.S. Mischenko, Q. Zhang, J.F. Scott, R.W. Whatmore, N.D. Mathur, Giant electrocaloric effect in thin-film $\mathrm{PbZr}_{0.95} \mathrm{Ti}_{0.05} \mathrm{O}_{3}$, Science 311 (5765) (2006) $1270-1271$.

[4] T.M. Correia, S. Kar-Narayan, J.S. Young, J.F. Scott, N.D. Mathur, R.W. Whatmore, Q. Zhang, PST thin films for electrocaloric coolers, Journal of Physics D-Applied Physics 44 (16) (2011).

[5] D. Saranya, A.R. Chaudhuri, J. Parui, S.B. Krupanidhi, Electrocaloric effect of PMN-PT thin films near morphotropic phase boundary, Bulletin of Materials Science 32 (3) (2009) 259-262.

[6] S.G. Lu, B. Rozic, Q.M. Zhang, Z. Kutnjak, R. Pirc, M. Lin, X. Li, L. Gorny, Comparison of directly and indirectly measured electrocaloric effect in relaxor ferroelectric polymers, Applied Physics Letters 97 (20) (2010).

[7] B. Neese, B. Chu, S.G. Lu, Y. Wang, E. Furman, Q.M. Zhang, Large electrocaloric effect in ferroelectric polymers near room temperature, Science 321 (5890) (2008) 
$821-823$.

[8] S.G. Lu, B. Rozic, Q.M. Zhang, Z. Kutnjak, B. Neese, Enhanced electrocaloric effect in ferroelectric poly(vinylidene-fluoride/trifluoroethylene) $55 / 45 \mathrm{~mol} \%$ copolymer at ferroelectric-paraelectric transition, Applied Physics Letters 98 (12) (2011).

[9] P.F. Liu, J.L. Wang, X.J. Meng, J. Yang, B. Dkhil, J.H. Chu, Huge electrocaloric effect in Langmuir-Blodgett ferroelectric polymer thin films, New Journal of Physics $12(6)(2010)$.

[10] X. Li, X.S. Qian, S.G. Lu, J. Cheng, Z. Fang, Q.M. Zhang, Tunable temperature dependence of electrocaloric effect in ferroelectric relaxor poly(vinylidene fluoride-trifluoroethylene-chlorofluoroethylene terpolymer, Applied Physics Letters 99 (5) (2011).

[11] M. Valant, Electrocaloric materials for future solid-state refrigeration technologies, Progress In Materials Science 57 (6) (2012) 980-1009.

[12] T. Takenaka, H. Nagata, Current status and prospects of lead-free piezoelectric ceramics, Journal of the European Ceramic Society 25 (12) (2005) 2693-2700.

[13] S. Zhang, R. Xia, T.R. Shrout, Lead-free piezoelectric ceramics vs. PZT?, Journal of Electroceramics 19 (4) (2007) 251-257.

[14] T. Takenaka, H. Nagata, Y. Hiruma, Current developments and prospective of lead-free piezoelectric ceramics, Japanese Journal of Applied Physics 47 (5) (2008) $3787-3801$.

[15] J. Roedel, W. Jo, K.T.P. Seifert, E.M. Anton, T. Granzow, D. Damjanovic, 
Perspective on the development of lead-free piezoceramics, Journal of the American Ceramic Society 92 (6) (2009) 1153-1177.

[16] A.B. Kounga, S.T. Zhang, W. Jo, T. Granzow, J. Roedel, Morphotropic phase boundary in (1-x) $\mathrm{Bi}_{0.5} \mathrm{Na}_{0.5} \mathrm{TiO}_{3}-\mathrm{xK}_{0.5} \mathrm{Na}_{0.5} \mathrm{NbO}_{3}$ lead-free piezoceramics, Applied Physics Letters 92 (22) (2008).

[17] S.T. Zhang, A.B. Kounga, E. Aulbach, H. Ehrenberg, J. Roedel, Giant strain in lead-free piezoceramics $\mathrm{Bi}_{0.5} \mathrm{Na}_{0.5} \mathrm{TiO}_{3}-\mathrm{BaTiO}_{3}-\mathrm{K}_{0.5} \mathrm{Na}_{0.5} \mathrm{NbO}_{3}$ system, Applied Physics Letters 91 (11) (2007).

[18] J. Tang, F. Wang, X. Zhao, H. Luo, L. Luo, W. Shi, Influence of the composition-induced structure evolution on the electrocaloric effect in $\mathrm{Bi}_{0.5} \mathrm{Na}_{0.5} \mathrm{TiO}_{3}$-based solid solution, Ceramics International 41 (4) (2015) 5888-5893.

[19] X.C. Zheng, G.P. Zheng, Z. Lin, Z.Y. Jiang, Electro-caloric behaviors of lead-free $\mathrm{Bi}_{0.5} \mathrm{Na}_{0.5} \mathrm{TiO}_{3}-\mathrm{BaTiO}_{3}$ ceramics, Journal of Electroceramics 28 (1) (2012) 20-26.

[20] W. Jo, S. Schaab, E. Sapper, L.A. Schmitt, H.J. Kleebe, A.J. Bell, J. Roedel, On the phase identity and its thermal evolution of lead free $\left(\mathrm{Bi}_{1 / 2} \mathrm{Na}_{1 / 2}\right) \mathrm{TiO}_{3}-6 \mathrm{~mol} \%$ $\mathrm{BaTiO}_{3}$, Journal of Applied Physics 110 (7) (2011).

[21] K.S. Rao, K.C.V. Rajulu, B. Tilak, A. Swathi, Effect of $\mathrm{Ba}^{2+}$ in BNT ceramics on dielectric and conductivity properties, Natural Science 02 (04) (2010) 357-367.

[22] L. Shebanovs, K. Borman, W. Lawless, A. Kalvane, Electrocaloric effect in some perovskite ferroelectric ceramics and multilayer capacitors, Ferroelectrics 273 (1) (2002) 137-142. 
[23] Y. Bai, G. Zheng, K. Ding, L. Qiao, S. Shi, The giant electrocaloric effect and high effective cooling power near room temperature for $\mathrm{BaTiO}_{3}$ thick film, Journal of applied physics 110 (9) (2011) 094103.

[24] X. Jiang, L. Luo, B. Wang, W. Li, H. Chen, Electrocaloric effect based on the depolarization transition in $(1-\mathrm{x}) \mathrm{Bi}_{0.5} \mathrm{Na}_{0.5} \mathrm{TiO}_{3}-\mathrm{x} \mathrm{KNbO}_{3}$ lead-free ceramics, Ceramics international 40 (2) (2014) 2627-2634.

[25] Q. Zheng, C. Xu, D. Lin, D. Gao, K.W. Kwok, Piezoelectric and ferroelectric properties of $\left(\mathrm{Bi}_{0.94-\mathrm{x}} \mathrm{La}_{\mathrm{x}} \mathrm{Na}_{0.94}\right)_{0.5} \mathrm{Ba}_{0.06} \mathrm{TiO}_{3}$ lead-free ceramics, Journal of Physics D-Applied Physics 41 (12) (2008).

[26] F. Chu, I.M. Reaney, N. Setter, Spontaneous (zero-field) relaxor-to-ferroelectric-phase transition in disordered $\mathrm{Pb}\left(\mathrm{Sc}_{1 / 2} \mathrm{Nb}_{1 / 2}\right) \mathrm{O}_{3}$, Journal of Applied Physics 77 (4) (1995) 1671-1676.

[27] J.K. Lee, J.Y. Yi, K.S. Hong, Dependence of incommensurate phase formation on vacancy type in La-doped $\left(\mathrm{Na}_{1 / 2} \mathrm{Ba}_{1 / 2}\right) \mathrm{TiO}_{3}$, Journal of Applied Physics 96 (2) (2004) 1174-1177.

[28] D. Thi Hinh, H.Y. Lee, C.H. Yoon, R.A. Malik, Y.M. Kong, J.S. Lee, T. Vu Diem Ngoc, Effect of lanthanum doping on the structural, ferroelectric, and strain properties of $\mathrm{Bi}_{1 / 2}\left(\mathrm{Na}_{0.82} \mathrm{~K}_{0.18}\right)_{1 / 2} \mathrm{TiO}_{3}$ lead-free ceramics, Journal of the Korean Physical Society 62 (7) (2013) 1004-1008.

[29] A. Hussain, A. Maqbool, R.A. Malik, A. Zaman, J.H. Lee, T.K. Song, J.H. Lee, W.J. Kim, M.H. Kim, Structural, dielectric and field-induced strain properties of La-modified $\mathrm{Bi}_{1 / 2} \mathrm{Na}_{1 / 2} \mathrm{TiO}_{3}-\mathrm{BaTiO}_{3}-\mathrm{SrZrO}_{3}$ ceramics, Korean Journal of Materials 
Research 25 (10) (2015) 566-570.

[30] X.X. Wang, H.L.W. Chan, C.L. Choy, $\left(\mathrm{Bi}_{0.5} \mathrm{Na}_{0.5}\right)_{0.94} \mathrm{Ba}_{0.06} \mathrm{TiO}_{3}$ lead-free ceramics with simultaneous addition of $\mathrm{CeO}_{2}$ and $\mathrm{La}_{2} \mathrm{O}_{3}$, Applied Physics a-Materials Science \& Processing 80 (2) (2005) 333-336.

[31] W. Jo, J. Roedel, Electric-field-induced volume change and room temperature phase stability of $\left(\mathrm{Bi}_{1 / 2} \mathrm{Na}_{1 / 2}\right) \mathrm{TiO}_{3}$-xmol\% $\mathrm{BaTiO}_{3}$ piezoceramics, Applied Physics Letters 99 (4) (2011).

[32] K. Wang, A. Hussain, W. Jo, J. Rödel, Temperature-dependent properties of $\left(\mathrm{Bi}_{1 / 2} \mathrm{Na}_{1 / 2}\right) \mathrm{TiO}_{3}-\left(\mathrm{Bi}_{1 / 2} \mathrm{~K}_{1 / 2}\right) \mathrm{TiO}_{3}-\mathrm{SrTiO}_{3}$ lead-free piezoceramics, Journal of the American Ceramic Society 95 (7) (2012) 2241-2247.

[33] J. Zylberberg, A. A. Belik, E. Takayama-Muromachi, Z.-G. Ye, Bismuth aluminate: a new high-Tc lead-free piezo-/ferroelectric, Chemistry of Materials 19 (26) (2007) 6385-6390.

[34] C. Ma, X. Tan, In situ transmission electron microscopy study on the phase transitionsin lead-free $(1-\mathrm{x})\left(\mathrm{Bi}_{1 / 2} \mathrm{Na}_{1 / 2}\right) \mathrm{TiO}_{3}-\mathrm{xBaTiO}_{3}$ ceramics, Journal of the American Ceramic Society 94 (11) (2011) 4040-4044.

[35] C. Ma, X. Tan, E. Dul'Kin, M. Roth, Domain structure-dielectric property relationship in lead-free $(1-\mathrm{x})\left(\mathrm{Bi}_{1 / 2} \mathrm{Na}_{1 / 2}\right) \mathrm{TiO}_{3}-\mathrm{xBaTiO}_{3}$ ceramics, Journal of applied physics 108 (10) (2010) 104105.

[36] C. Ma, X. Tan, Phase diagram of unpoled lead-free (1-x) $\left(\mathrm{Bi}_{1 / 2} \mathrm{Na}_{1 / 2}\right) \mathrm{TiO}_{3}-\mathrm{xBaTiO}_{3}$ ceramics, Solid State Communications 150 (33-34) (2010) 1497-1500. 
[37] A. Ullah, C.W. Ahn, A. Ullah, I.W. Kim, Large strain under a low electric field in lead-free bismuth-based piezoelectrics, Applied Physics Letters 103 (2) (2013).

[38] G. Smolenskii, V. Isupov, A. Agranovskaya, N. Krainik, New ferroelectrics of complex composition, Soviet Physics-Solid State 2 (11) (1961) 2651-2654.

[39] S. Ke, H. Fan, H. Huang, H.L. Chan, Lorentz-type relationship of the temperature dependent dielectric permittivity in ferroelectrics with diffuse phase transition, Applied physics letters 93 (11) (2008) 112906.

[40] B. Peng, H. Fan, Q. Zhang, The contribution of the "extrinsic" polarizations to the dielectric tunability of $\mathrm{Pb}\left(\mathrm{Mg}_{1 / 3} \mathrm{Nb}_{2 / 3}\right)_{1-\mathrm{x}} \mathrm{Ti}_{\mathrm{x}} \mathrm{O}_{3}$ relaxor ferroelectrics, Journal of the American Ceramic Society 95 (5) (2012) 1651-1655.

[41] F. Wang, M. Xu, Y. Tang, T. Wang, W. Shi, C.M. Leung, Large strain response in the ternary $\mathrm{Bi}_{0.5} \mathrm{Na}_{0.5} \mathrm{TiO}_{3}-\mathrm{BaTiO}_{3}-\mathrm{SrTiO}_{3}$ solid solutions, Journal of the American Ceramic Society 95 (6) (2012) 1955-1959.

[42] A. Ullah, C.W. Ahn, A. Hussain, I.W. Kim, The effects of sintering temperatures on dielectric, ferroelectric and electric field-induced strain of lead-free $\mathrm{Bi}_{0.5}\left(\mathrm{Na}_{0.78} \mathrm{~K}_{0.22}\right)_{0.5} \mathrm{TiO}_{3}$ piezoelectric ceramics synthesized by the sol-gel technique, Current Applied Physics 10 (6) (2010) 1367-1371.

[43] W. Jo, T. Granzow, E. Aulbach, J. Rodel, D. Damjanovic, Origin of the large strain response in $\left(\mathrm{K}_{0.5} \mathrm{Na}_{0.5}\right) \mathrm{NbO}_{3}$-modified $\left(\mathrm{Bi}_{0.5} \mathrm{Na}_{0.5}\right) \mathrm{TiO}_{3}-\mathrm{BaTiO}_{3}$ lead-free piezoceramics, Journal of Applied Physics 105 (9) (2009) 094102.

[44] I. Ponomareva, S. Lisenkov, Bridging the macroscopic and atomistic descriptions of the electrocaloric effect, Physical review letters 108 (16) (2012) 167604. 
[45] G. Sebald, S. Pruvost, L. Seveyrat, L. Lebrun, D. Guyomar, B. Guiffard, Electrocaloric properties of high dielectric constant ferroelectric ceramics, Journal of the European Ceramic Society 27 (13) (2007) 4021-4024.

[46] L.J. Dunne, M. Valant, A. Axelsson, G. Manos, N.M. Alford, Statistical mechanical lattice model of the dual-peak electrocaloric effect in ferroelectric relaxors and the role of pressure, Journal of Physics D: Applied Physics 44 (37) (2011) 375404.

[47] G. Lin, X. Xiong, J. Zhang, Q. Wei, Latent heat study of phase transition in $\mathrm{Ba}_{0.73} \mathrm{Sr}_{0.27} \mathrm{TiO}_{3}$ induced by electric field, Journal of thermal analysis and calorimetry $81(1)(2005) 41-44$.

[48] M. Valant, L.J. Dunne, A.-K. Axelsson, N.M. Alford, G. Manos, J. Peräntie, J. Hagberg, H. Jantunen, A. Dabkowski, Electrocaloric effect in a ferroelectric $\mathrm{Pb}\left(\mathrm{Zn}_{1 / 3} \mathrm{Nb}_{2 / 3}\right) \mathrm{O}_{3}-\mathrm{PbTiO}_{3}$ single crystal, Physical Review B 81 (21) (2010) 214110. 


\section{Figures and Caption}

Figure 1. a) XRD patterns of $\left[\left(\mathrm{Bi}_{1 / 2} \mathrm{Na}_{1 / 2}\right)_{0.94} \mathrm{Ba}_{0.06}\right]_{(1-1.5 \mathrm{x})} \mathrm{La}_{\mathrm{x}} \mathrm{TiO}_{3} \quad(\mathrm{x}=0,0.03,0.06$, 0.09) ceramics, b) Enlarged (111) and (002) profiles of $\left[\left(\mathrm{Bi}_{1 / 2} \mathrm{Na}_{1 / 2}\right)_{0.94} \mathrm{Ba}_{0.06}\right]_{(1-1.5 \mathrm{x})} \mathrm{La}_{\mathrm{x}} \mathrm{TiO}_{3} \quad(\mathrm{x}=0,0.03,0.06,0.09)$.

Figure 2. The surface SEM images of $\left[\left(\mathrm{Bi}_{1 / 2} \mathrm{Na}_{1 / 2}\right)_{0.94} \mathrm{Ba}_{0.06}\right]_{(1-1.5 \mathrm{x})} \mathrm{La}_{\mathrm{x}} \mathrm{TiO}_{3}$ ceramics after thermal etched. a) $x=0, b) x=0.03, c) x=0.06$ and d) $x=0.09$.

Figure 3. The $\varepsilon(T)$ and tan $\delta(T)$ of $\left[\left(\mathrm{Bi}_{1 / 2} \mathrm{Na}_{1 / 2}\right)_{0.94} \mathrm{Ba}_{0.06}\right]_{(1-1.5 \mathrm{x})} \mathrm{La}_{\mathrm{x}} \mathrm{TiO}_{3}$ ceramics under different frequencies and the Lorentz fitting of the $\varepsilon(T)$ at $100 \mathrm{~Hz}$ (dot line). a) x $=0, \mathrm{~b}$ ) $\mathrm{x}=0.03, \mathrm{c}) \mathrm{x}=0.06$ and d) $\mathrm{x}=0.09$.

Figure 4. $P-E$ curves of $\left[\left(\mathrm{Bi}_{1 / 2} \mathrm{Na}_{1 / 2}\right)_{0.94} \mathrm{Ba}_{0.06}\right]_{(1-1.5 \mathrm{x})} \mathrm{La}_{\mathrm{x}} \mathrm{TiO}_{3}$ ceramics at selected temperatures. a) $x=0, b) x=0.03, c) x=0.06$ and d) $x=0.09$.

Figure 5. The $(\partial P / \partial T)_{E}(T)$ curves and $P(T)$ curves (inset) of $\left[\left(\mathrm{Bi}_{1 / 2} \mathrm{Na}_{1 / 2}\right)_{0.94} \mathrm{Ba}_{0.06}\right]_{(1-1.5 \mathrm{x}} \mathrm{La}_{\mathrm{x}} \mathrm{TiO}_{3}$ ceramics at selected electric fields. a) $\mathrm{x}=0$, b) $\mathrm{x}=$ $0.03, \mathrm{c}) \mathrm{x}=0.06$ and $\mathrm{d}) \mathrm{x}=0.09$.

Figure 6. The $\Delta T(T)$ of $\left[\left(\mathrm{Bi}_{1 / 2} \mathrm{Na}_{1 / 2}\right)_{0.94} \mathrm{Ba}_{0.06}\right]_{(1-1.5 \mathrm{x})} \mathrm{La}_{\mathrm{x}} \mathrm{TiO}_{3}$ ceramics at selected electric fields. a) $\mathrm{x}=0, \mathrm{~b}) \mathrm{x}=0.03, \mathrm{c}) \mathrm{x}=0.06$ and d) $\mathrm{x}=0.09$.

Figure 7. The $\Delta S(T)$ of $\left[\left(\mathrm{Bi}_{1 / 2} \mathrm{Na}_{1 / 2}\right)_{0.94} \mathrm{Ba}_{0.06}\right]_{(1-1.5 \mathrm{x})} \mathrm{La}_{\mathrm{x}} \mathrm{TiO}_{3}$ ceramics at selected electric fields. a) $\mathrm{x}=0, \mathrm{~b}) \mathrm{x}=0.03, \mathrm{c}) \mathrm{x}=0.06$ and d) $\mathrm{x}=0.09$. 
a)

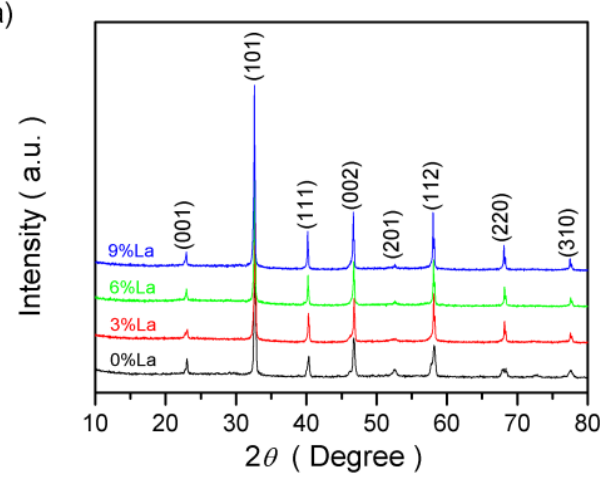

b)

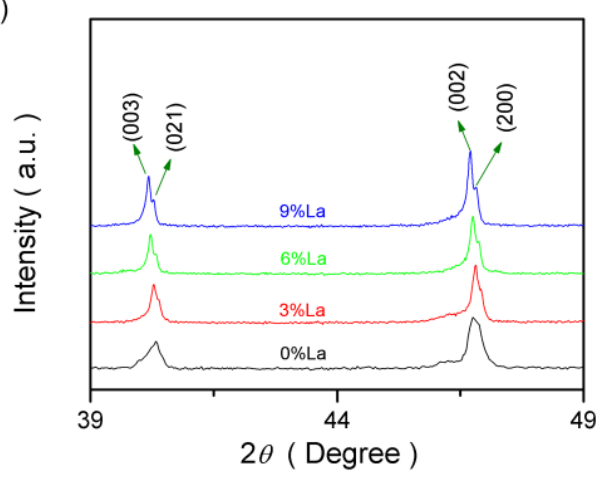

Figure 1 

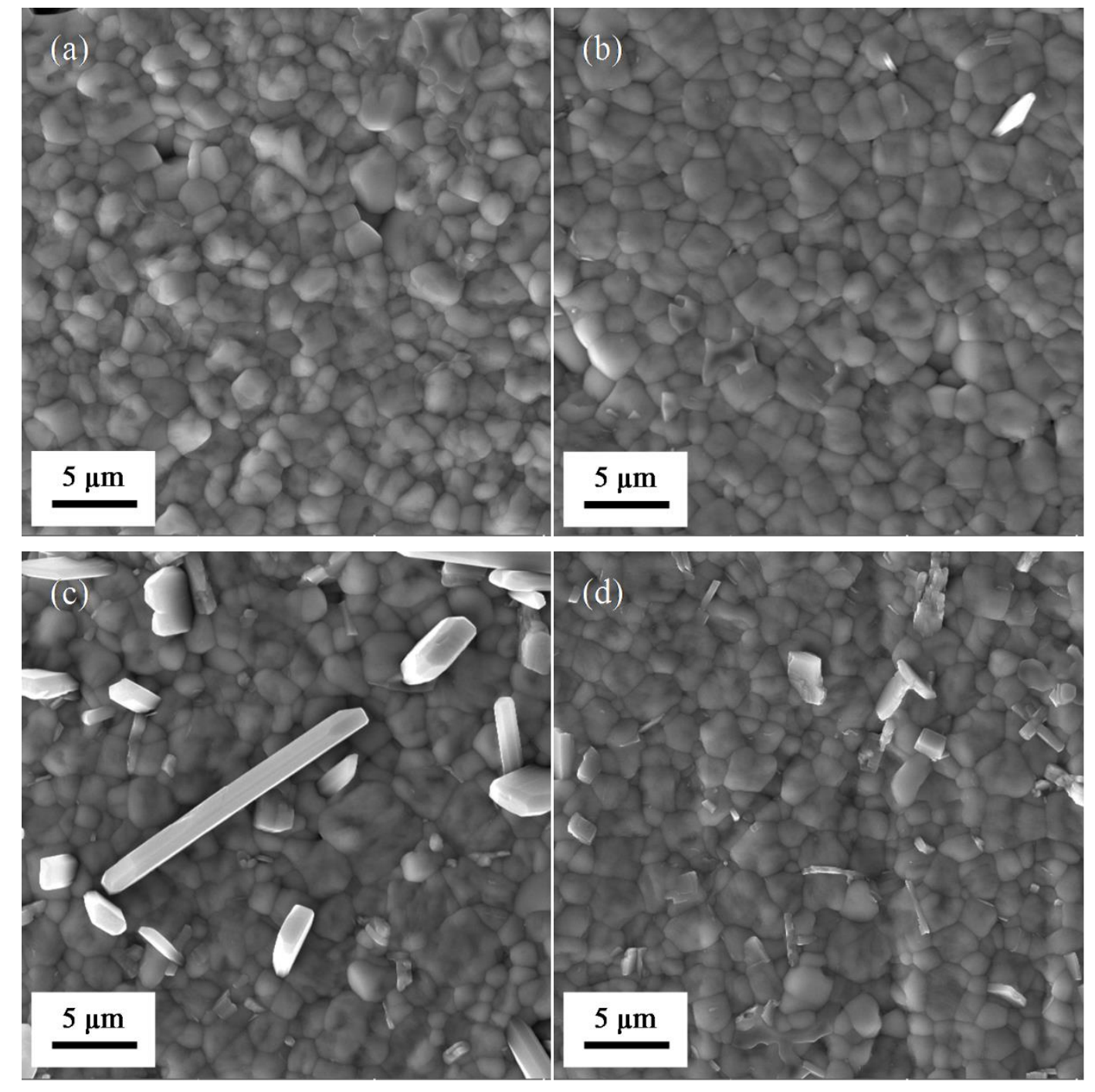

Figure 2 

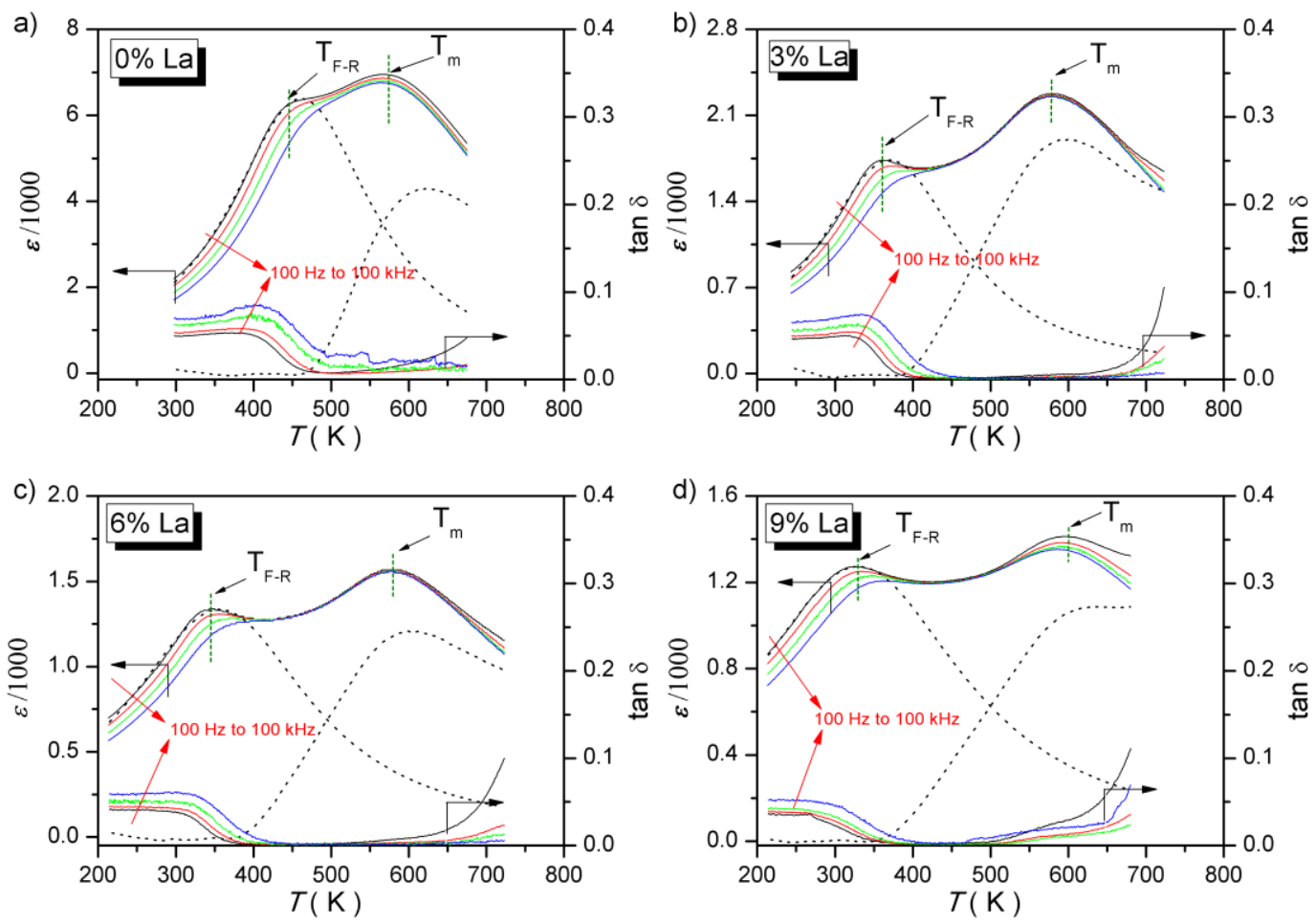

Figure 3 

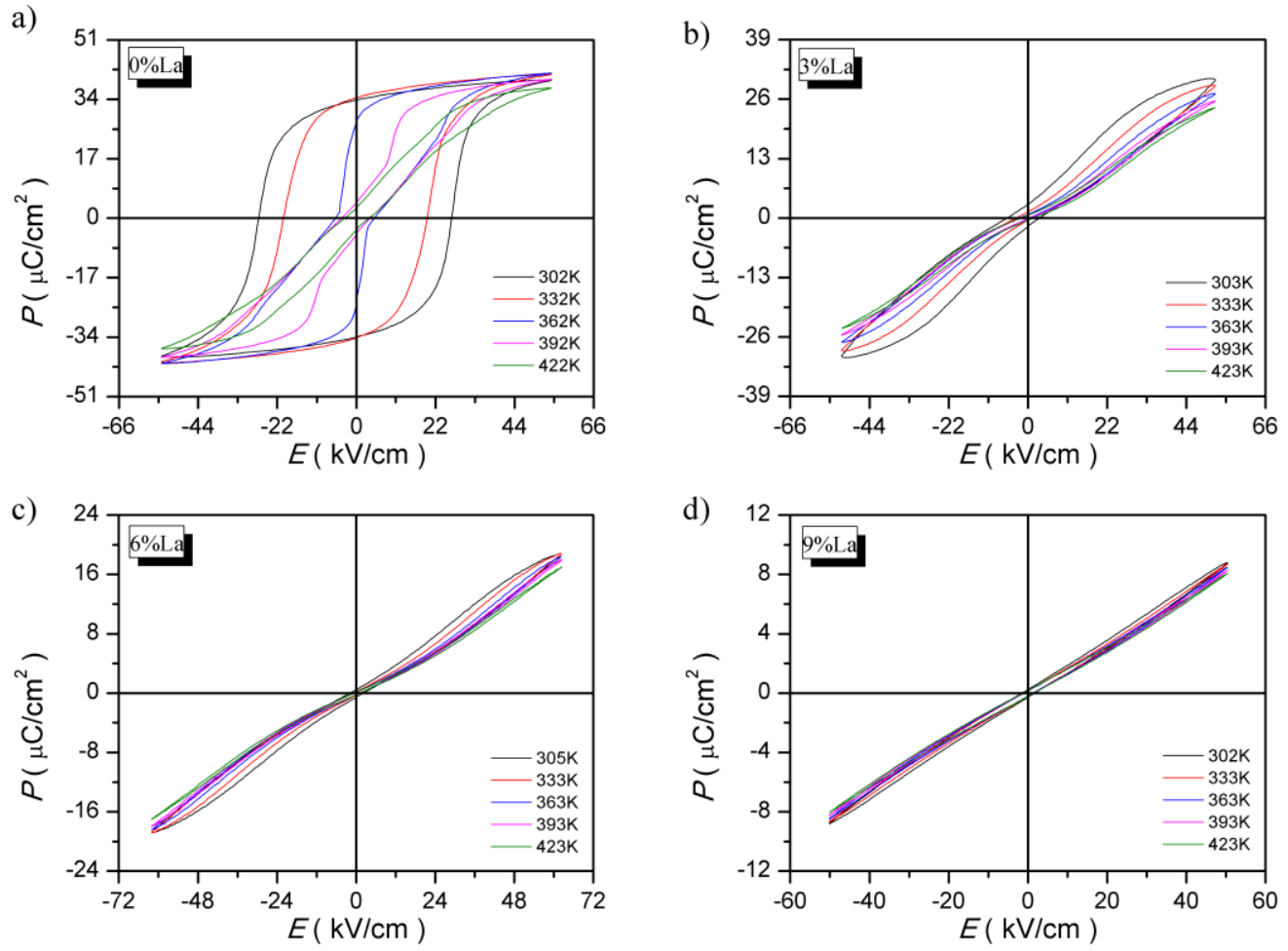

Figure 4 

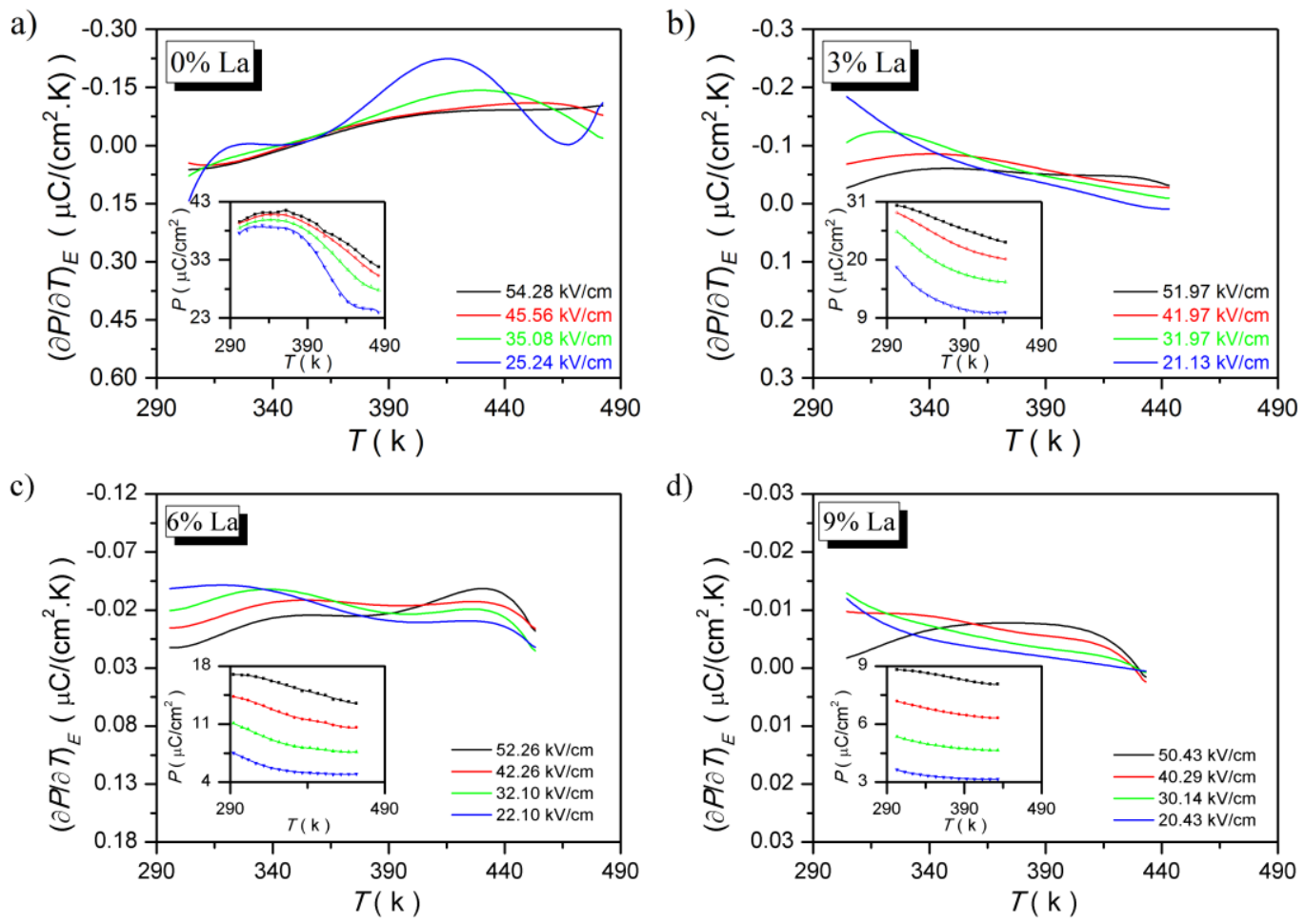

Figure 5 

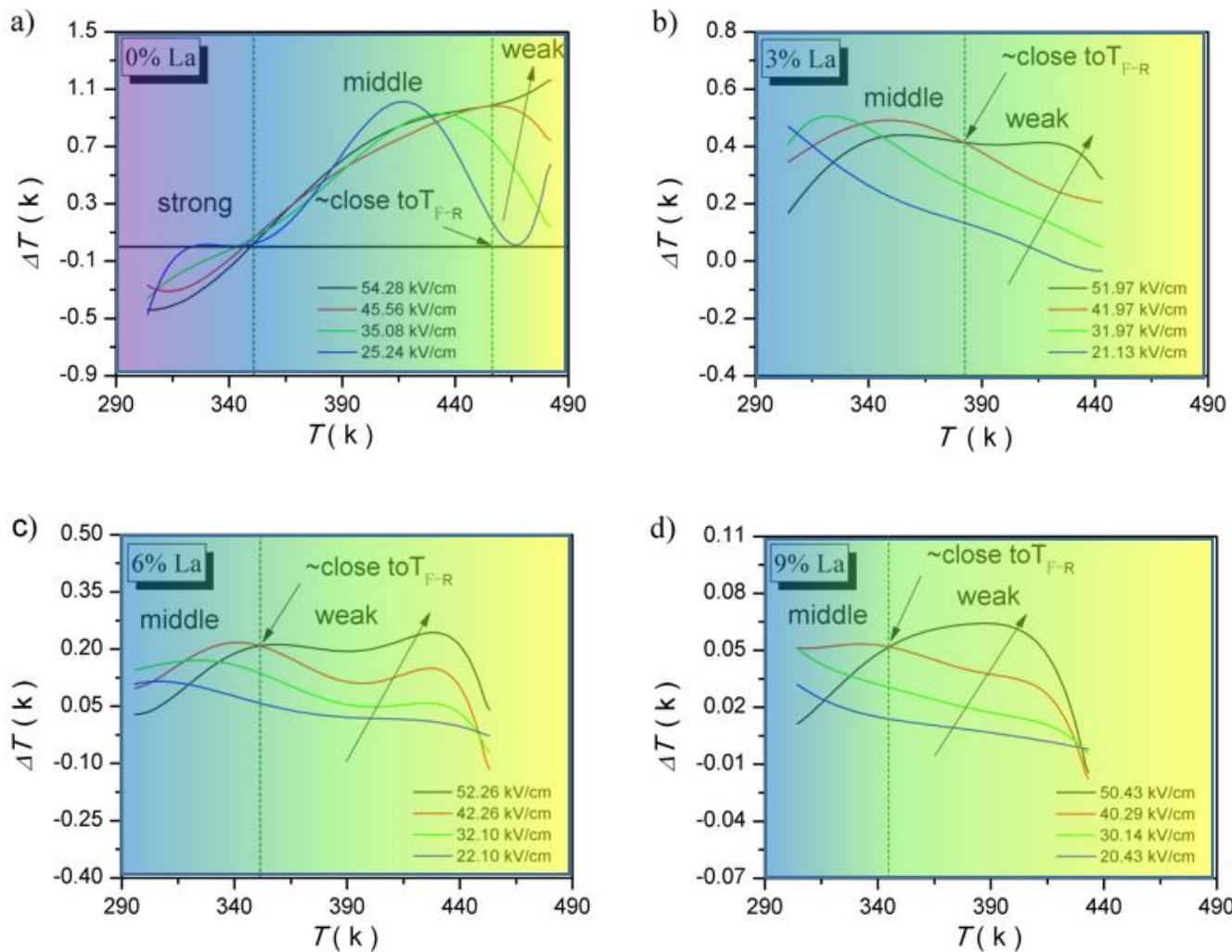

\section{Figure 6}



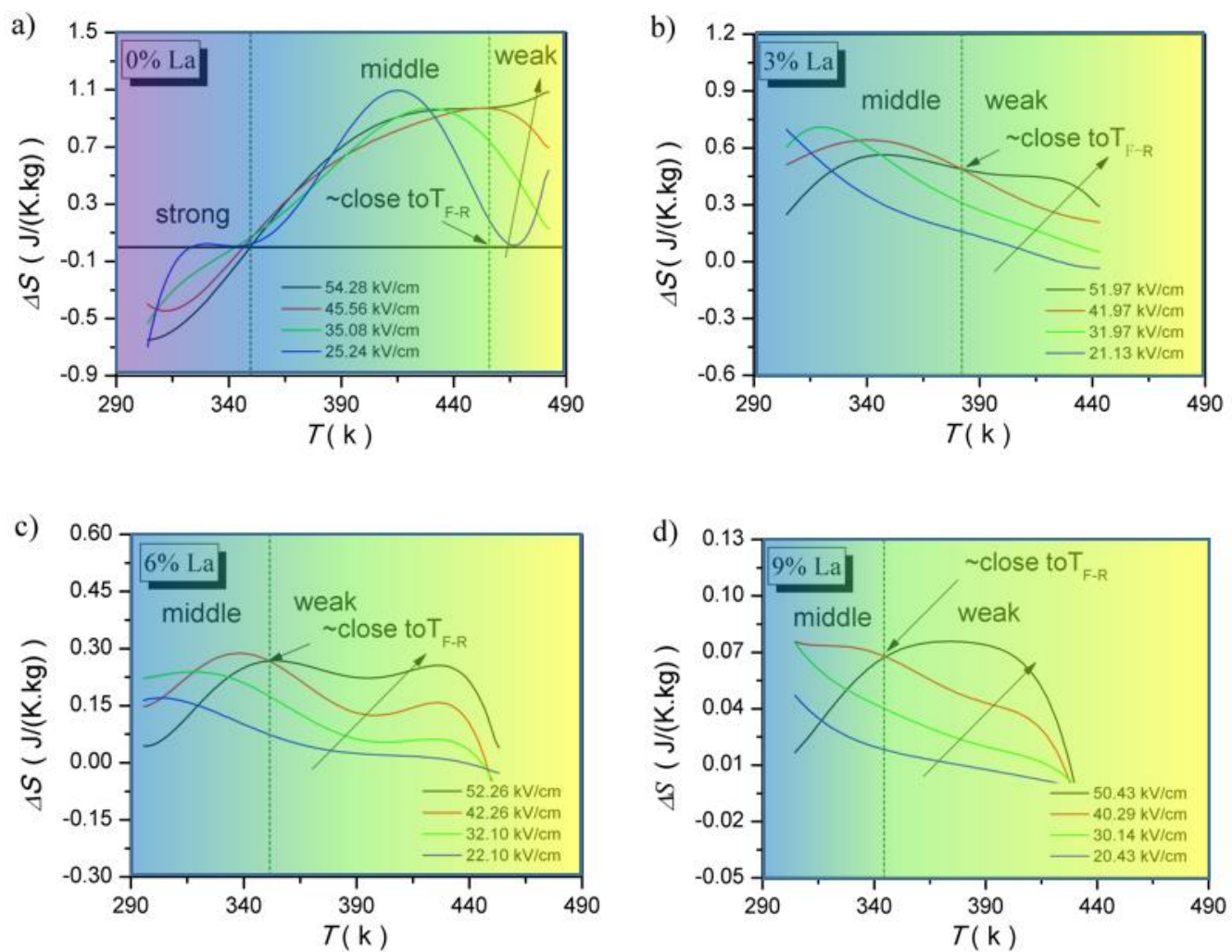

Figure 7 
Table 1. Lorentz fitting results of the temperature dependence of the $\varepsilon(T)$ of $\left[\left(\mathrm{Bi}_{1 / 2} \mathrm{Na}_{1 / 2}\right)_{0.94} \mathrm{Ba}_{0.06}\right]_{(1-1.5 \mathrm{x})} \mathrm{La}_{\mathrm{x}} \mathrm{TiO}_{3}(\mathrm{x}=0,0.03,0.06,0.09)$ ceramics at $100 \mathrm{~Hz}$.

\begin{tabular}{cccccc}
\hline Sample & $T_{\mathrm{A}}(\mathrm{K})$ & $\varepsilon_{\mathrm{A}}$ & $\delta_{\mathrm{A}}(\mathrm{K})$ & $T_{\mathrm{m}}(\mathrm{K})$ & $\varepsilon_{\mathrm{m}}$ \\
\hline 0.0 & 461 & 6.38 & 80 & 570 & 6.95 \\
0.03 & 370 & 1.74 & 82 & 574 & 2.27 \\
0.06 & 356 & 1.34 & 101 & 580 & 1.56 \\
0.09 & 330 & 1.27 & 118 & 585 & 1.41 \\
\hline
\end{tabular}



2017-09-22

\title{
Electrocaloric effect in La-doped BNT-6BT relaxor ferroelectric ceramics
}

\author{
Li, Lucheng
}

Elsevier

Li L, Xu M, Zhang Q, et al., Electrocaloric effect in La-doped BNT-6BT relaxor ferroelectric ceramics. Ceramics International, Volume 44, Issue 1, January 2018, Pages 343-350

http://dx.doi.org/10.1016/j.ceramint.2017.09.179

Downloaded from Cranfield Library Services E-Repository 